\title{
The Adsorption of Organic Pollutants by Gemini Surfactant-Modified Montmorillonite from Water
}

\author{
Zhenghua Wang* \\ Hunan Provincial Key Laboratory of Shale Gas Resource Exploitation, Hunan University of Science \& Technology, China
}

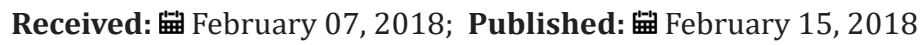

*Corresponding author: Zhenghua Wang, Hunan Provincial Key Laboratory of Shale Gas Resource Exploitation, Hunan University of Science \& Technology, Xiangtan,411201, China

\section{Mini Review}

Water is a very important resource to human life and the development of society. But large amounts of natural and anthropogenic organic substances are constantly discharged to water bodies. The serious problem of water pollution has been raising a global concern. These typical organic contaminants in water environment include but not limited to dyes, pharmaceuticals and personal care products (PPCPs), phenols and polycyclic aromatic hydrocarbons (PAHs). Most of those compounds are toxic to aquatic biota and human beings [1]. Therefore, removal of this organic matter from water is a great subject of research nowadays. Off all the removal methods, adsorption is an effective technique which is widely used. Various adsorbents have been studied that include materials based on carbon, clay minerals, polymers, silica, and so on [1]. Clay minerals are considered as low cost and easily available adsorbents. Montmorillonite, a 2:1 layered dioctahedral aluminosilicate of smectite group clay, is one of the most investigated clay minerals for removing organic pollutants because of its versatility and facile modification of its porosity, acidity, hydrophilicity, and so on [2]. But natural montmorillonite is not a suitable and effective adsorbent, so it is necessary to modify the surface of montmorillonite to improve its physico-chemical properties and value in use. Organic surface modification is one of the most extensive technologies among those modifying methods, and the modifiers are usually conventional surfactants.

Gemini surfactants are a new generation of surfactant which possess at least two hydrophobic chains and two ionic or polar groups, and a great deal of variation exists in the nature of spacers [3]. Comparing to conventional surfactants, Gemini surfactants have many good properties, such as lower critical micelle concentration (CMC), higher efficiency in reducing the oil/ water interfacial tension, better wetting, Solubilizing, foaming, and antibacterial activities [4]. Recently, Gemini surfactant have gained much attention as modifier of montmorillonite. It has been found that organo-montmorillonite modified with Gemini surfactants exhibited better efficacy in removing organic contaminants from water in comparison to its monomer-modified montmorillonite [4]. This article attempts to give a brief review of removal of various organic pollutants by Gemini surfactant modified montmorillonite.

\section{Removal of dyes from aqueous solutions}

Preparation of organo-montmorillonites by using three novel Gemini cationic surfactants (Gemini 12-2-12, 12-3-12 and 18-3-18) under microwave irradiation were reported by Liu B, et al. [5]. Adsorption efficiency of methyl orange dye on montmorillonites and three kinds of organo-montmorillonites was also evaluated by Liu B, et al. [5]. The results show that all organomontmorillonites displayed more excellent adsorption capacities than montmorillonites. Gu Z, et al. [6]. Prepared another Gemini surfactant modified montmorillonite (BDHP-Mt). Batch adsorption experiments were performed to remove methyl orange and Congo red from aqueous solutions using BDHP-Mt. The results indicated that BDHP-Mt exhibited much higher adsorption capacities than active carbon, which implied that BDHP-Mt could be used as an alternative adsorbent of active carbon or other common adsorption materials for removing dyes from effluents [6]. Modification of montmorillonite by using Gemini surfactants with different spacer chain length and different alkyl chain length were investigated by Luo Z, et al. [7] and Ren HP, et al. [2], respectively. The adsorption behavior of methyl orange from aqueous solution onto organ clays was determined. The results indicated that the adsorption capacity of the organ clays was in the order: 16-4-16-Mt>16-8-16-Mt>166-16-Mt (different spacer chain length) [7] and 16-2-16-Mt>18-218-Mt>12-2-12-Mt (different alkyl chain length) [2]. These works provide a deep insight into the interaction of Gemini-modified montmorillonites and methyl orange. 


\section{Removal of phenols from aqueous solutions}

The adsorption of a series of Gemini surfactants, $[\mathrm{CnH} 2 \mathrm{n}+1 \mathrm{~N}+(\mathrm{CH} 3) 2-\mathrm{CH} 2 \mathrm{CH} 2] 2 \cdot 2 \mathrm{Br}-$, where $\mathrm{n}=10,12,14$ and 16 , on Na-montmorillonite and this adsorption on the removal of 2-naphthol and 4-chlorophenol have been studied by Li F, Rosen MJ, et al. [8,9]. The results of these two pollutants onto Namontmorillonite treated by either the Gemini or the conventional surfactants show that the former are more efficient and more effective at removing 2-naphthol and 4-chlorophenol from the aqueous solutions. Later, Yang S, et al. $[4,10]$ used different Gemini surfactants (include a novel aromatic-containing Gemini surfactant) to modify Na-montmorillonite. And the comparative study for the adsorption of 2-naphthol and phenol from aqueous solution was performed. The results also suggested that the adsorption amount of 2-naphthnol was much higher than that of phenol under the same condition, which may be attributed to the stronger hydrophobicity of 2-naphthnol and its higher delocalized $\pi$-electron density. The removal of p-nitro phenol using Gemini surfactants modified montmorillonites from aqueous solutions was studied by Xue G, et al. [11]. The results revealed that the adsorption of p-nitro phenol increases with an increase in $\mathrm{pH}$ and adsorbent mass.

\section{Removal of Antimicrobials from Aqueous Solutions}

Different ester-containing Gemini surfactant-modified montmorillonites (EMMT) were prepared under microwave irradiation by Liu B, et al. [12]. His study systematically discussed the adsorption properties of EMMT by assessing the adsorption is other for triclosan (a kind of antimicrobial agent). The result showed that Langmuir isothermal adsorption model could describe the adsorption behavior better; the adsorption behavior of triclosan on EMMT was confirmed to a surface monolayer adsorption. In 2014, Lu L, et al. [13] also confirmed that a kind of Gemini surfactantmodified montmorillonites (BHDAP-Mt) could effectively remove sulfamethoxazole (SMX, a kind of antimicrobials) from aqueous solutions. Results showed that the adsorption capacity increased with the initial SMX concentration and contact time but decreased with increasing solution ionic strength. Equilibrium data were best represented by the Langmuir model.

\section{Conclusion}

In this review, the adsorption of different organic pollutants (include organic dyes, phenols and antimicrobials) by different Gemini surfactant-modified montmorillonite have been summarized. From literatures, we can see that montmorillonites modified with Gemini surfactants show better efficacy in removing organic contaminants from water in comparison to its monomermodified montmorillonite. Undoubtedly, Gemini surfactantmodified montmorillonite will be used as an alternative adsorbent of activated carbon or other common adsorbents for removal of organic pollutants from water.

\section{References}

1. Sajid M, Nazal MK, Baig N, Osman AM (2018) Removal of heavy metals and organic pollutants from water using dendritic polymers based adsorbents: A critical review. Separation and Purification Technology 19: 400-423.

2. Ren HP, Tian SP, Zhu M (2018) Modification of montmorillonite by Gemini surfactants with different chain lengths and its adsorption behavior for methyl orange. Applied Clay Science 151: 29-36.

3. Hait SK, Moulik SP (2002) Gemini surfactants: A distinct class of selfassembling molecules. Current Science 82(9): 1101-1111.

4. Yang S, Gao M, Luo Z (2014) Adsorption of 2-Naphthol on the organomontmorillonites modified by Gemini surfactants with different spacers. Chemical Engineering Journal 256: 39-50.

5. Liu B, Wang X, Yang B, Sun R (2011) Rapid modification of montmorillonite with novel cationic Gemini surfactants and its adsorption for methyl orange. Materials Chemistry and Physics 130: 1220-1226.

6. Gu Z, Gao M, Luo Z, Xue G, Lu L, et al. (2014) Gemini surfactant modified montmorillonite as highly efficient adsorbent for anionic dyes. Separation Science and Technology 49(18): 2878-2889.

7. Luo Z, Gao M, Ye Y, Yang S (2015) Modification of reduced-charge montmorillonites by a series of Gemini surfactants: Characterization and application in methyl orange removal. Applied Surface Science 324: 807-816.

8. Li F, Rosen MJ (2000) Adsorption of Gemini and conventional cationic surfactants onto montmorillonite and the removal of some pollutants by the clay. Journal of Colloid and Interface Science 224(2): 265-271.

9. Rosen MJ, Li F (2001) The adsorption of Gemini and conventional surfactants onto some solids and the removal of 2-Naphthol by the soil surfaces. Journal of Colloid and Interface Science 234(2): 418-424.

10. Yang S, Gao M, Luo Z, Yang Q (2015) The characterization of organomontmorillonite modified with a novel aromatic-containing gemini surfactant and its comparative adsorption. Chemical Engineering Journal 268: 125-134.

11. Xue G, Gao M, Gu Z, Luo Z, Hu Z (2013) The removal of p-nitrophenol from aqueous solutions by adsorption using gemini surfactants modified montmorillonites. Chemical Engineering Journal 218: 223-231.

12. Liu B, Lu J, Xie Y, Yang B, Wang X, et al. (2014) Microwave-assisted modification on montmorillonite with ester-containing Gemini surfactant and its adsorption behavior for triclosan. Journal of Colloid and Interface Science 418: 311-316.

13. Lu L, Gao M, Gu Z, Yang S, Liu Y (2014) A comparative study and evaluation of sulfamethoxazole adsorption onto organo-montmorillonites. Journal of Environmental Sciences 26: 2535-2545. 
(C) (P) ${ }_{\text {BY }}^{\text {This work is licensed under Creative }}$

To Submit Your Article Click Here:

Submit Article

DOI: $10.32474 /$ MAOPS.2018.01.000106

Modern Approaches in Oceanography and
Petrochemical Sciences

